\title{
Microtubule Formation and Activities of Antioxidative Enzymes in PC12 Cells Exposed to Phosphatidylcholine Hydroperoxides
}

\author{
Yukako Yamanaka *, Shumi Yoshida-Yamamoto and Hiroshi Doi \\ Department of Food Science and Nutrition, Mukogawa Women's University, Nishinomiya, \\ Hyogo 663-8558, Japan; E-Mails: syoshida@mukogawa-u.ac.jp (S.Y.-Y.); \\ hiroshid@mukogawa-u.ac.jp (H.D.) \\ * Author to whom correspondence should be addressed; E-Mail: yamayuka@ mukogawa-u.ac.jp; \\ Tel./Fax: +81-798-45-9883.
}

Received: 9 November 2012; in revised form: 19 November 2012 / Accepted: 20 November 2012 / Published: 22 November 2012

\begin{abstract}
Aging increases free radical generation and lipid oxidation and, thereby, mediates neurodegenerative diseases. As the brain is rich in lipids (polyunsaturated fatty acids), the antioxidative system plays an important role in protecting brain tissues from oxidative injury. The changes in microtubule formation and antioxidative enzyme activities have been investigated in rat pheochromocytoma PC12 cells exposed to various concentrations of phosphatidylcholine hydroperoxides ( $\mathrm{PCOOH})$. We measured three typical antioxidative enzymes, superoxide dismutase (SOD), glutathione peroxidase (GPx), and catalase (CAT). The microtubule assembly system was dependent on the antioxidative enzyme system in cells exposed to oxidative stress. The activities of the three enzymes increased in a $\mathrm{PCOOH}$ exposure-dependent manner. In particular, the changes in the activity as a result of $\mathrm{PCOOH}$ exposure were similar in the three antioxidative enzymes. This is the first report indicating the compatibility between the tubulin-microtubule and antioxidative enzyme systems in cells that deteriorate as a result of phospholipid hydroperoxide administration from an exterior source. The descending order of sensitivity of the three enzymes to $\mathrm{PCOOH}$ is also discussed.
\end{abstract}

Keywords: neurodegeneration; oxidative stress; phosphatidylcholine hydroperoxide; lipid; antioxidative enzyme 


\section{Introduction}

Microtubules are important components of several subcellular structures, including the mitotic apparatus, cilia, flagella, and neurons, and play many roles in cellular processes, such as cell division, cell motility, and morphogenesis, which are required for brain function. A cellular shrinkage and a decrease in cell number have been observed. Matsuyama et al. [1] have hypothesized that impairment of the microtubule system is important to explain the pathogenesis of Alzheimer's disease (AD). In addition, it has been reported that the AD brain has decreased synapse density [2]. Iqbal et al. [3] have reported on the inhibition of microtubule formation due to the kubextensive phosphorylation of the tau protein, which leads to microtubule degeneration in $\mathrm{AD}$. We have reported on the inhibition of microtubule formation by phosphatidylcholine hydroperoxides (PCOOH) from soybean phosphatidylcholine (PC) [4]. The PCOOH used here was obtained by photooxidation of soybean PC. The high performance liquid chromatograms (HPLC) of $\mathrm{PCOOH}$ and $\mathrm{PC}$ are as found in the references. Soybean PC is mainly composed of palmitic acid (16:0) and linoleic acid (18:2). This PC is used in place of human cell PC. We have also presented some evidence of nerve cell dysfunction caused by microtubule disorder [5]. A remarkable increase of lipid peroxides in the brain with dementia has also been reported [6-8]. Using a neural cell line, PC12, it has been demonstrated that the damage of microtubules by beta-amyloid causes morphological abnormalities in the cell [9]. It is well known that oxidative stress plays a crucial role in neurodegenerative diseases, such as AD [10,11]. Organisms have developed mechanisms for their protection against oxidative stress. Intercellular ROS production and propagation are controlled by highly complex and integrated antioxidant systems [12]. The antioxidant enzymes in our body play an important part in aging. Enzymes, such as superoxide dismutase (SOD), glutathione peroxidase (GPx), and catalase (CAT), make up the most important endogenous antioxidant system. There are some papers investigating alterations in the antioxidant enzyme activities and an oxidative damage in different tissues of diabetic animals $[13,14]$. We have focused the compatibility between the tubulin-microtubule and antioxidative enzyme systems in cells exposed to oxidative damage. Lipid peroxidation products accumulate in the brains of people with $\mathrm{AD}$, whereas the enzymatic antioxidant system exists in the brain. We found, too, that even very low concentrations of $\mathrm{PCOOH}$ are sufficient to interfere with a component of microtubule tubulin; therefore, microtubule formation and the interaction mechanism are hydrophobic [15]. As mentioned before, the $\mathrm{PCOOH}$ used in this study was obtained by photooxidation of soybean PC. The composition of soybean PC is similar to that of, for example, human platelet PC, which is composed mainly of palmitic acid (16:0) and eicosapentaenoic acid [16]. Although soybean PC is used instead of PC from human cells, behavior of PCOOH from soybean and human cells are thought to be similar. As the interaction between $\mathrm{PCOOH}$ and tubulin is hydrophobic in nature [4], we can expect to observe similar damage in cells exposed to human platelet PCOOH and cells exposed to soybean $\mathrm{PCOOH}$. Considering that neurodegenerative diseases, such as $\mathrm{AD}$, are induced by a microtubule disorder based on oxidative stress, endogenous enzymatic antioxidant systems are very important from the viewpoint of protection from such diseases. There are no data about the relationship between microtubule formation and the enzymatic antioxidant system in cells exposed to oxidative stress, whereas data on the disproportion between free radical levels and the enzymatic antioxidant system in cerebral regions of the aging rat have been reported [17]. It is very 
important to examine the comparative data from the viewpoint of the use of another nonenzymatic antioxidant system for the prevention of and protection from oxidative stress. We proposed in earlier research [18] that our experimental system using PCOOH and PC12 cells may be a good model of brain cells in the early stages of neurodegenerative diseases and showed microtubule formation in the cell in the presence of PCOOH. In addition, cell viability was significantly decreased in PC12 cells treated with $\mathrm{PCOOH}$. Also our results with immunofluorescence microscopy using an anti- $\alpha$-tubulin antibody revealed that $\mathrm{PCOOH}$ degrades tubulin and disrupts microtubules. These results led us to consider that the precise target of $\mathrm{PCOOH}$ in the neuron might be tubulin. The aim of this study is to clarify the effect of the disintegration of the antioxidant enzymatic system on microtubule formation in PC12 cells exposed to $\mathrm{PCOOH}$ and gather information on a precise target of $\mathrm{PCOOH}$. Achieving this goal is dependent on assessing whether the increased $\mathrm{PCOOH}$, as oxidative stress, causes the dysfunction of the antioxidant enzymatic systems of SOD, GPx, and CAT and the microtubule disorder by measuring guanosine triphosphatase (GTPase) activity as a putative index for microtubule formation.

\section{Results}

\subsection{Inhibition of Microtubule Formation by $\mathrm{PCOOH}$}

Neurites consist mainly of microtubules, whose function is significantly based on the ability of tubulin to polymerize and depolymerize. Guanosine-5'-triphosphatase (GTPase) activity is an indicator of microtubule formation and, therefore, provides the degree of microtubule assembly [19-21].

Figure 1. Guanosine-5'-triphosphatase (GTPase) activity of differentiated PC12 cells exposed to phosphatidylcholine (PC) or 0, 20, 50, 70 and $100 \mu \mathrm{mol} / \mathrm{L}$ phosphatidylcholine hydroperoxides $(\mathrm{PCOOH})$. Differentiated $\mathrm{PC} 12$ cells were incubated in a medium containing PC or PCOOH for $24 \mathrm{~h}$. The GTPase activity in the cell lysates was assayed by measuring the increase of guanosine diphosphate GDP by high performance liquid chromatography (HPLC) described in the previous report [15]. The data represent the means \pm SD. ${ }^{*} p<0.01$ compared with the control value.

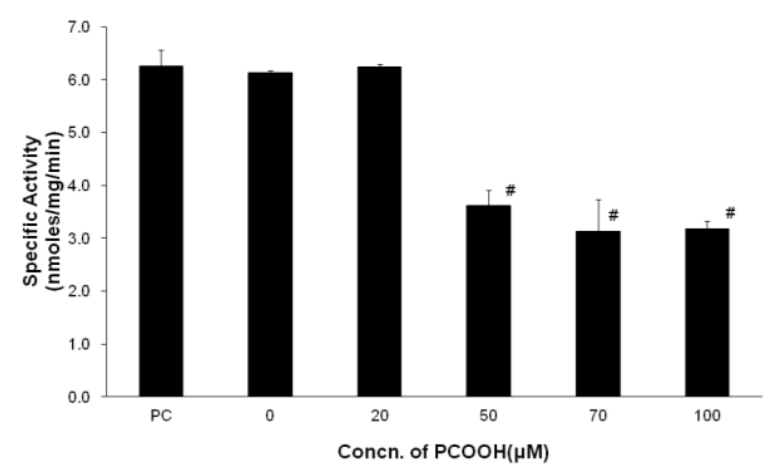

We measured the GTPase activity of cell extracts derived from differentiated PC12 cells exposed to different concentrations of PCOOH (Figure 1). The GTPase activity of cells exposed to $20 \mu \mathrm{M}$ $\mathrm{PCOOH}$ hardly changed compared with that of cells incubated in the absence of PCOOH. The specific activity of GTPase of differentiated PC12 cells was decreased by half by exposure to $50 \mu \mathrm{M} \mathrm{PCOOH}$. On the other hand, the activity was almost the same for $50 \mu \mathrm{M} \mathrm{PCOOH}$ exposure and $100 \mu \mathrm{M} \mathrm{PCOOH}$ 
exposure, while the $\mathrm{PCOOH}$ concentration increased from $50 \mu \mathrm{M}$ to $100 \mu \mathrm{M}$. The microtubule formation pattern of differentiated PC12 cells exposed to $\mathrm{PCOOH}$ was a reverse sigmoid according to the PCOOH concentration, as shown in Figure 1. Microtubule formation was inhibited by PCOOH [4]. Native phosphatidylcholine (PC) and $20 \mu \mathrm{M}$ PCOOH exposures did not seem to affect microtubule formation due to the endogenous antioxidative system, and excess $\mathrm{PCOOH}$ was not eliminated by the system.

\subsection{Effects of PCOOH on SOD Activities}

The enzyme SOD exists in the cytoplasm of all cells in great abundance. SOD catalyzes the breakdown of the superoxide anion $\left(\mathrm{O}_{2} \bullet^{-}\right)$by transforming the superoxide anion into a product, such as hydrogen peroxide. SOD eliminates the superoxide, which creates the hydroxyl radical in the presence of iron and cupper ion. Hydrogen peroxide is metabolized to water by GPx. SOD is mainly located in neurons. These findings mean that SOD provides the first line of defense against oxygen toxicity in neurons.

We measured the SOD activity of differentiated PC12 cells exposed to PCOOH at various concentrations for $24 \mathrm{~h}$ using a SOD measurement kit. As shown in Figure 2, cells exposed to $50 \mu \mathrm{M}$ $\mathrm{PCOOH}$ showed highly increased SOD activity relative to those exposed to $20 \mu \mathrm{M}$ PCOOH. In cases of cells exposed to 50, 70, and $100 \mu \mathrm{M} \mathrm{PCOOH}$, the SOD activities were significantly higher than those of cells exposed to no or $20 \mu \mathrm{M}$ PCOOH. The SOD activity of cells exposed to 50, 70, and $100 \mu \mathrm{M}$ PCOOH increased 1.69-, 1.74-, and 1.84-fold, respectively, relative to that of those exposed to no $\mathrm{PCOOH}$. The effect of native PC was not significant.

Figure 2. Superoxide dismutase (SOD) activity of differentiated PC12 cells exposed to PC or $0-100 \mu \mathrm{mol} / \mathrm{L} \mathrm{PCOOH}$. After incubation in the presence of $\mathrm{PC}$ or $\mathrm{PCOOH}$, the original medium was removed, and cells were lysed with a Nonidet P-40 lysis buffer. The level of SOD activity in the cell lysates was measured using the SOD Assay Kit-WST (Dojindo Molecular Technologies, Inc., Gaithersburg, MD, USA) according to the manufacturer's instructions. Data are experiments as percent of the control; the mean value was obtained from six experiments. The data represent the means \pm SD. ${ }^{*} p<0.01$ compared with the control value.

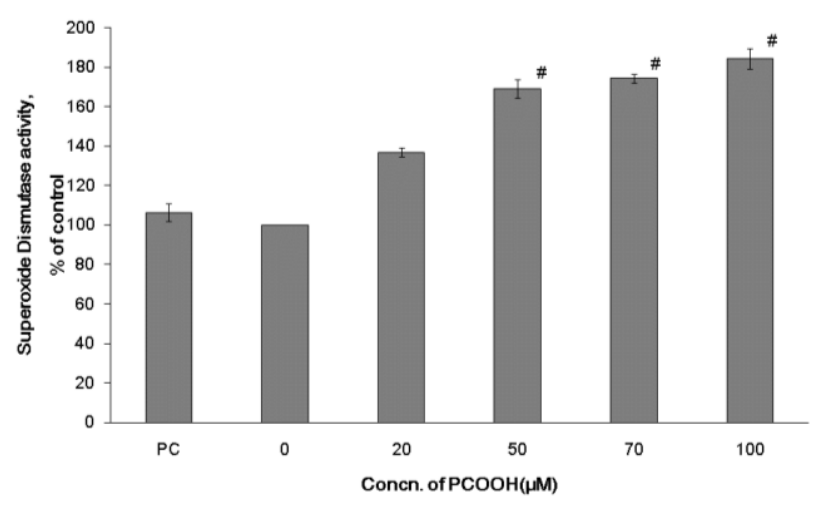

The SOD activity of the PC12 cell increased depending on the PCOOH concentration in the presence of over $50 \mu \mathrm{M} \mathrm{PCOOH}$. The activity seemed to increase in order to eliminate $\mathrm{O}_{2}{ }^{-}$in the cells 
induced by $\mathrm{PCOOH}$. The facts obtained in this experiment support the idea that SOD activity can be induced by peroxidative stress [22].

\subsection{Effects of PCOOH on GPx Activities}

GPx reduces hydrogen peroxide generated from the dismutation of $\mathrm{O}_{2}{ }^{-}$by SOD and exchanges hydroperoxides from membrane lipid and free fatty acid into corresponding alcohols within a cell. Therefore, GPx protects intracellular ingredients from oxidative denaturation and plays a role in stabilizing each organelle membrane. GPx is an essential factor for the viability of aerobic organisms.

As shown in Figure 3, the GPx activity increased by $8.2 \%$ of the control value of the PC12 cell with $20 \mu \mathrm{M}$ PCOOH exposure. The GPx activity significantly increased by $65.7 \%, 79.1 \%$, and $75.8 \%$, respectivey, with exposure to $\mathrm{PCOOH}$ at concentrations of 50, 70, and $100 \mu \mathrm{M}$ compared with the value with no PCOOH. There is a slight difference between the GPx activity with no exposure to PCOOH and that with exposure to $20 \mu \mathrm{M}$. However, the GPx activity went up rapidly when changing the PCOOH concentration from 20 to $50 \mu \mathrm{M}$. In the case of cells incubated under the condition of 50-100 $\mu \mathrm{M}$ PCOOH exposure, the GPx activity was almost the same. The capability to eliminate hydrogen peroxide from the cells exposed to $50 \mu \mathrm{M}$ PCOOH was higher than that from cells exposed to $20 \mu \mathrm{M}$ PCOOH. The GPx activity pattern with the PCOOH concentration was sigmoidal, as shown in Figure 3.

Figure 3. Glutathione peroxidase (GPx) activity of differentiated $\mathrm{PC} 12$ cells exposed to $0-100 \mu \mathrm{mol} / \mathrm{L} \mathrm{PCOOH}$. After incubation in the presence of $\mathrm{PCOOH}$, the cells were washed with ice-cold phosphate buffered saline (PBS), and homogenized in a lysis solution containing $5 \mathrm{mM}$ EDTA/0.01\% digitonin/0.25\% sodium chlorate. After centrifugation, the enzymes in the supernatants were assayed [23]. The activity of GPx was measured with the Bioxytech GPx-340 kit. Data are experiments as percent of the control; the mean value was obtained from six experiments. The data represent the means \pm SD. ${ }^{\#} p<0.01$ compared with the control value.

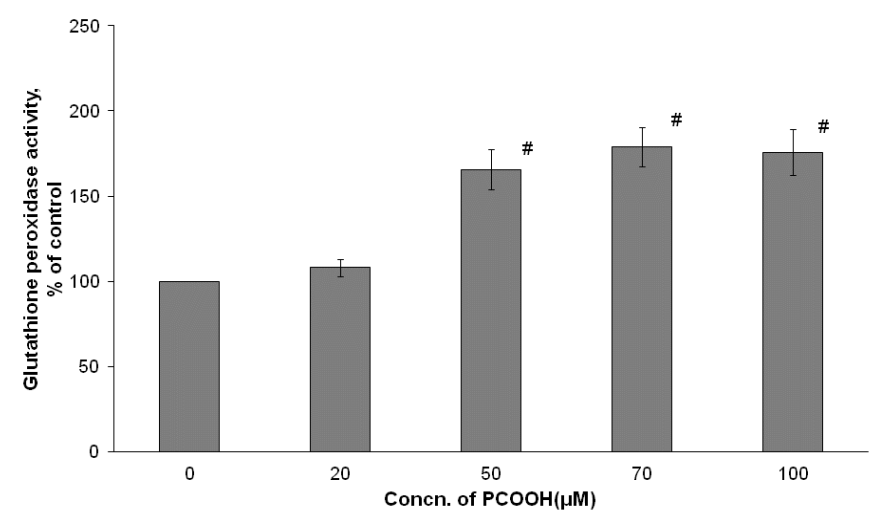

\subsection{Effects of PCOOH on CAT Activities}

CAT is one of the most abundant enzymes in nature and is widely distributed throughout tissues in the animal and plant kingdom. At the cellular level, it is located in the cytosol. This enzyme is involved in the destruction of hydrogen peroxide generated during cellular metabolism. 
Figure 4 shows that the intracellular CAT activity became higher with $50-100 \mu \mathrm{M} \mathrm{PCOOH}$ exposure than with no $\mathrm{PCOOH}$ exposure. While exposures to native $\mathrm{PC}$ and $20 \mu \mathrm{M} \mathrm{PCOOH}$ had no effect on the activity, exposures to 50,70 , and $100 \mu \mathrm{M}$ PCOOH significantly increased the CAT activity of differentiated PC12 cells, and the increase percentiles were 65.3\%, 71.5\%, and 117.3\%, respectively. There was no significant difference between the CAT activity of cells exposed to $50 \mu \mathrm{M}$ PCOOH and that of those exposed to $70 \mu \mathrm{M} \mathrm{PCOOH}$ (Figure 4). The increase of CAT activity by exposure to $\mathrm{PCOOH}$ appeared to be composed of two steps under experimental conditions. The first step was observed between the exposure to $20 \mu \mathrm{M} \mathrm{PCOOH}$ and that to $50 \mu \mathrm{M} \mathrm{PCOOH}$, and the next, between the exposure to $70 \mu \mathrm{M} \mathrm{PCOOH}$ and that to $100 \mu \mathrm{M} \mathrm{PCOOH}$. The tendency of the activity changes observed in CAT was very similar to that observed in GPx. The activity of CAT in the cells exposed to $\mathrm{PCOOH}$ became extremely large when raising the $\mathrm{PCOOH}$ concentration from $20 \mu \mathrm{M}$ to $50 \mu \mathrm{M}$ in the medium. The results indicate that CAT activity is induced by an excess amount of substrate.

Figure 4. Catalse (CAT) activity of PC12 cells exposed to PC or 0-100 $\mu \mathrm{mol} / \mathrm{L} \mathrm{PCOOH}$. After incubation in the presence of $\mathrm{PC}$ or $\mathrm{PCOOH}$, a phosphate buffer, methanol, $\mathrm{H}_{2} \mathrm{O}_{2}$, and distilled water were mixed. Then, the mixed solution, sample protein, and a phosphate buffer were incubated for $20 \mathrm{~min}$, and Purpald was added. The mixture was incubated for $20 \mathrm{~min}$. Finally, potassium periodate was added, and the absorbance was measured at $550 \mathrm{~nm}$. Data are experiments as percent of the control; the mean value was obtained from six experiments. The data represent the means \pm SD. ${ }^{\#} p<0.01$ compared with the control value.

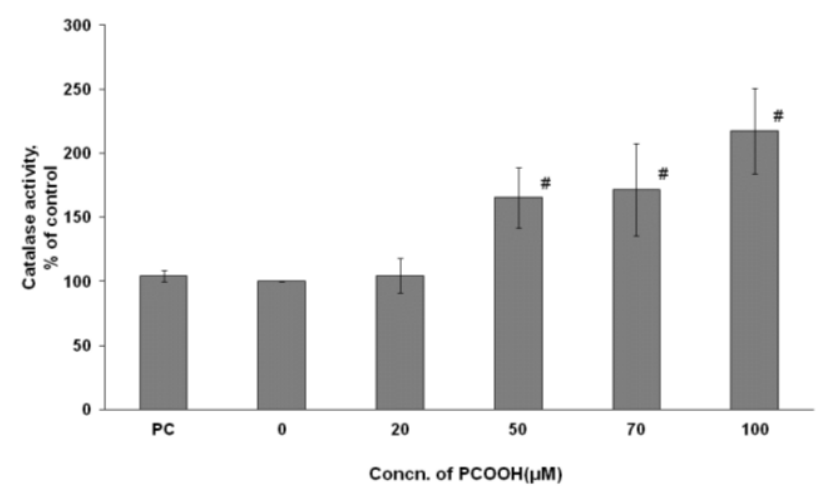

\section{Discussion}

To understand the correlation between neurodegenerative diseases and microtubule disorders, we have been studying the effects of lipid hydroperoxides on microtubule formation [5]. In an earlier paper, we showed that $\mathrm{PCOOH}$ inhibited neurite outgrowth through microtubule disorders in PC12 cells [18]. Therefore, it is biologically interesting to elucidate the behavior of endogenous antioxidative systems under oxidative stress in neuronal cells. In addition, reports on the tubulin-microtubule system of neurodegenerative diseases are sparse. This is the first report indicating the association between the tubulin-microtubule system and enzymatic antioxidative systems in cells under oxidative stress. Furthermore, the most sensitive enzyme among the antioxidative enzymes is suggested to be SOD by specifying the enzyme that responded to the lowest concentration of PCOOH (Figure 2). 
It is widely accepted that oxidative stress is significantly related to the development of disease and that this relationship increases in connection with many lifestyle-related diseases and aging [22,24-26]. There have been numerous studies on reactive oxygen species and aging since the relationship between them was initially proposed by Harman [27-31]. Furthermore, it is clear that reactive oxygen species, such as hydrogen peroxide, hydroperoxides, and free radicals, oxidize directly with biomolecules and organelles and also act as signal messengers in intracellular communication [32].

Considering the effects of oxidative stress, it is important to examine the balance of antioxidative defenses, repair of oxidative damage, and generation of oxidants as well as products due to reactive oxygen species [33]. Humans have various defense networks that include anti-oxidization elements and enzymatic antioxidative systems that protect against oxidative stress. Antioxidant enzymes are important protective mechanisms against oxidative stress [34-36].

In this study, we examined the change of enzymatic antioxidative systems in response to $\mathrm{PCOOH}$ as an oxidative stressor in differentiated PC12 cells. The PCOOH concentrations to which cells were exposed were $0,20,50,70$, and $100 \mu \mathrm{M}$ in the culture medium in order to clarify the effects of $\mathrm{PCOOH}$ on both antioxidant enzymatic activity and microtubule formation, while they were 0,50 , and $100 \mu \mathrm{M}$ in our previous report [18]. The GTPase activity of differentiated PC12 cells incubated under a culture condition of $20 \mu \mathrm{M}$ PCOOH was slightly lower than that under a condition of no $\mathrm{PCOOH}$ (Figure 1). The GTPase activities of differentiated PC12 cells decreased much more significantly with exposures to over $50 \mu \mathrm{M}$ PCOOH than did those of cells exposed to $20 \mu \mathrm{M}$ PCOOH. This is the first report in which the effect of phosphatidylcholine hydroperoxides on microtubule formation has been observed in detail.

In parallel with the results of GTPase activity, a microtubule disorder was not observed when the PCOOH concentration to which differentiated PC12 cells were exposed was under $20 \mu \mathrm{M}$. On the other hand, raising the $\mathrm{PCOOH}$ concentration to $50 \mu \mathrm{M}$ induced a decrease of microtubule formation (Figure 1). The concentration of oxidants in cells increases with age. The results shown in Figure 1 indicate that a microtubule disorder might appear in an aged neuronal cell. In other words, the endogenous antioxidant system was insufficient to maintain normal microtubule formation. This indicates that another exogenous antioxidant system is necessary to protect microtubule formation.

The antioxidant enzyme system in the cell exposed to PCOOH worked to eliminate hydrogen peroxide, phospholipid hydroperoxide, and superoxide. The GTPase activity of cells exposed to $20 \mu \mathrm{M}$ $\mathrm{PCOOH}$ was not different from that of cells exposed to no $\mathrm{PCOOH}$.

Even when differentiated PC 12 cells were exposed to $20 \mu \mathrm{M}$ PCOOH, SOD was activated, while GPx was activated with exposure to $50 \mu \mathrm{M} \mathrm{PCOOH}$ (Figures 2 and 3). In the case of CAT, the exposure to $50 \mu \mathrm{M}$ PCOOH resulted in a slight increase, and that to $100 \mu \mathrm{M}$ PCOOH produced a large increase (Figure 4). These results indicate that antioxidant enzymes were activated in the presence of PCOOH by SOD, GPx, and CAT, in that order. This order also indicates the sensitivity among the examined enzymes.

In the case of cells incubated with over $50 \mu \mathrm{M}$ PCOOH, recovery of GTPase activity (tubulin-microtubule system) was not observed, while the three antioxidative enzymes caused its activity to increase. This result indicates the limitations of the ability of an antioxidative enzyme to remove oxidative stress induced by hydrogen peroxide, lipid hydroperoxides, and superoxide. 
The changes in the GTPase activity and the antioxidative enzyme induced by exposure of cells to $\mathrm{PCOOH}$ are associated. This means that these enzyme activities are associated with each other and depend on the remaining amount of reactive oxygen species (Figures 1-4).

When differentiated PC12 cells were exposed to $\mathrm{PCOOH}$, the enzymatic antioxidative systems did not change markedly under $20 \mu \mathrm{M}$, and a significant surge in the activities was observed over $50 \mu \mathrm{M}$. The same patterns were observed in the assay using three enzymes.

The effect of $\mathrm{PCOOH}$ exposure on microtubule formation and antioxidative enzymes was compatible. For example, the pattern indicated in Figure 3 is the complete reverse of that in Figure 1, indicating that the effect of $\mathrm{PCOOH}$ on microtubule formation was associated with the induction of enzymatic antioxidative systems by lipid hydroperoxides. This means that the precise target would be $\mathrm{PCOOH}$ in aged cells.

As described in a previous paper, this experimental system might be a good model for clarifying the aging mechanism by lipid hydroperoxides. The result obtained in this study supports a proposal in our previous study that one of the targets of $\mathrm{PCOOH}$ is tubulin. In a typical protective system, reactive oxygen species derived from $\mathrm{PCOOH}$ would be eliminated and cells would function satisfactorily. On the other hand, even if antioxidative enzyme activities arise in response to an excess concentration of $\mathrm{PCOOH}$, the reactive oxygen species that is cleaved completely would remain in a cell. The concentration of phosphatidylcholine hydroperoxides used in this paper was appropriately compared with that present in living cells. Although phosphatidylcholine hydroperoxides resulted in the increase of the three main antioxidative enzyme activities in this study, GTPase activity decreased. This fact indicates that microtubule formation was not sufficient. These phenomena would be possible in living cells and would lead to aging and neurodegenerative diseases. Antioxidative enzymes were effective in eliminating reactive oxygen species, but the results of GTPase activity obtained in this study suggest that the enzymes were not effective in this regard. This leads to the deterioration of cell function by reactive oxygen species. It is assumed that an enzymatic antioxidative system would not work in cases of aging and neurodegenerative diseases. Our findings in this study identifying the compatibility of GTPase activity and antioxidative enzyme activity are very important for the understanding of the function of a brain with dementia.

In this study, we examine the compatibility of microtubule formation and antioxidative enzyme activity. The use of exogenous antioxidants should be considered for the removal of superoxide anions based on their sensitivity to exposure to oxidative stress. It is important to observe the behavior of microtubule formation in the presence of various antioxidants. Experiments using antioxidants are now in progress.

\section{Experimental Section}

\subsection{Materials}

PC12 cells were purchased from Dainippon Sumitomo Pharma Co., Ltd. (Osaka, Japan). Fetal bovine serum (FBS), horse serum (HS), and penicillin/streptomycin were obtained from ICN Biomedicals, Inc. (Aurora, OH, USA). Nerve growth factor-7S (NGF-7S) was from Sigma Chemical Co. (St. Louis, MO, USA). The RPMI-1640 medium was obtained from GIBCO Invitrogen Corporation 
(New York, NY, USA). The starting material used to prepare phosphatidylcholine hydroperoxide (PCOOH) was Lipoid S-100, a soybean phosphatidylcholine (PC), which is essentially pure PC, obtained from Nisshin Oilio Group, Ltd. (Tokyo, Japan). The method for preparing PCOOH has been described previously [15]. For example, $20 \mu \mathrm{M}$ hydroperoxide corresponded to $0.038 \mathrm{mg} / \mathrm{mL}$ of $\mathrm{PCOOH}$. The concentration of $\mathrm{PCOOH}$ used here was several times higher than that used for ino measurements [37-39]. To assess the causes of cell damage, we performed a series of experiments using normal phospholipids as substitutes for $\mathrm{PCOOH}$ at the same concentrations. Chemicals used were of reagent grade.

\subsection{Cell Culture}

The PC12 cell line was derived from transplantable rat adrenal pheochromocytoma [40]. Differentiated cells were used in every experiment discussed in this paper. Differentiated cells were more sensitive to phosphatidylcholine hydroperoxides than undifferentiated cells described in our previous paper [18], which suggested that microtubules were an important target of phosphatidylcholine hydroperoxides. PC12 cells were propagated in an RPMI-1640 medium containing $10 \%$ heat-inactivated HS, $5 \%$ heat-inactivated FBS, and $0.3 \%$ penicillin/streptomycin. Cells were cultured at $37{ }^{\circ} \mathrm{C}$ in humidified $95 \%$ air with $5 \% \mathrm{CO}_{2}$. The cells differentiated into responding NGF by induction of the neuronal phenotype. For differentiation, the undifferentiated cells were seeded on dishes or plates. After $24 \mathrm{~h}$ of incubation, the culture medium was replaced with a fresh medium containing $0.5 \%$ HS and $100 \mathrm{ng} / \mathrm{mL}$ NGF-7S. All cells were cultured in collagen-coated culture dishes, flasks, or plates.

\subsection{Exposure of PC12 Cells to PCOOH}

Differentiated PC12 cells were exposed to $\mathrm{PCOOH}$ by replacing the RPMI medium containing $1 \%$ HS and $100 \mathrm{ng} / \mathrm{mL}$ NGF-7S with PCOOH at a concentration between 0 and $100 \mu \mathrm{M}$, and cells were incubated for $24 \mathrm{~h}$. The concentration of $\mathrm{PCOOH}$ was determined by its extinction coefficient at $233 \mathrm{~nm}$, as described before $[4,18]$. Before the enzyme assay experiments, cells were washed with the RPMI-1640 medium and gathered by centrifugation.

\subsection{Assay of GTPase Activity}

Differentiated PC12 cells were incubated in a medium containing PC or $0,20,50,70$, and $100 \mu \mathrm{M}$ $\mathrm{PCOOH}$ for $24 \mathrm{~h}$. Treated cells were gathered by centrifugation and disrupted using a mini-beater (Biospace Products, Bartlesville, OK, USA) in a $10 \mathrm{mM}$ sodium phosphate buffer, $\mathrm{pH}$ 7.0. After brief centrifugation, the cell lysate was obtained. The GTPase assay was performed by adding an aliquot of supernatant to a $10 \mathrm{mM}$ sodium phosphate buffer, $\mathrm{pH}$ 7.0, containing $0.1 \mathrm{mM}$ GTP, $3.4 \mathrm{M}$ glycerol, and $10 \mathrm{mM} \mathrm{MgCl}_{2}$. GDP, the reaction product, was quantified by the HPLC system according to a previous report [15]. The protein quantity was determined with the Bradford protein assay (Bio-Rad Laboratories Inc., Hercules, CA, USA). 


\subsection{Antioxidant Enzymes}

\subsubsection{Determination of SOD Activity}

The level of SOD activity in differentiated PC12 cells was measured using the SOD Assay Kit-WST (Dojindo Molecular Technologies Inc., Gaithersburg, MD, USA) according to a protocol described previously [41]. After incubation of the cells with the experimental reagents for $24 \mathrm{~h}$, the original medium was removed from the 96-well plate, and the cells were lysed with the Nonidet P-40 lysis buffer (1\% NP-40, $50 \mathrm{mmol} / \mathrm{L}$ Tris- $\mathrm{HCl}(\mathrm{pH} 7.5), 0.05 \mathrm{mM}$ ethylenediamine tetra-acetate) for $20 \mathrm{~min}$ at $4{ }^{\circ} \mathrm{C}$. The lysates were centrifuged at $300 \times g$ for $10 \mathrm{~min}$, and $20 \mu \mathrm{L}$ of the supernatant was used for determination of the SOD activity according to the manufacturer's instructions. The value for each treatment group was converted to the percentage control.

\subsubsection{Measurement of GPx Activities}

Differentiated PC12 cells were centrifuged, washed with ice-cold PBS, and homogenized in $500 \mu \mathrm{L}$ of a lysis solution containing $5 \mathrm{mM}$ EDTA/0.01\% digitonin/ $0.25 \%$ sodium chlorate. After centrifugation at $10,000 \times g$ for $30 \mathrm{~min}$ at $4{ }^{\circ} \mathrm{C}$, the enzymes in the supernatants were assayed [23]. The activity of GPx was measured with the Bioxytech GPx-340 kit (OXIS International, Portland, OR, USA).

\subsubsection{Determination of CAT Activity}

The CAT activity was determined as previously described [42]. Briefly, a $0.25 \mathrm{M}$ phosphate buffer, $12 \mathrm{M}$ methanol, $44 \mathrm{mM} \mathrm{H} \mathrm{H}_{2} \mathrm{O}_{2}$, and distilled water were mixed. Then, the mixed solution, sample protein, and a phosphate buffer were incubated for $20 \mathrm{~min}$, and Purpald (Sigma-Aldrich, St. Louis, MO, USA) (25 mM in $2 \mathrm{~N}$ potassium hydroxide) was added to formaldehyde made from the reaction as a coloring substrate; the mixture was incubated for $20 \mathrm{~min}$. Finally, $65.2 \mathrm{mM}$ of potassium periodate was added to stop the reaction completely, and the absorbance of the purple formaldehyde adduct was measured at $550 \mathrm{~nm}[43]$.

\subsection{Statistical Analysis}

Data are expressed as means and standard deviations. Differences in the mean values were assessed for significance by one-way analysis of variance (ANOVA). To compare undifferentiated and differentiated cells, the non-paired $t$-test was applied.

\section{Conclusions}

It is important to observe the behavior of microtubule formation as well as antioxidative enzyme activities of cells deteriorated by $\mathrm{PCOOH}$ because microtubules play have roles, such as cell division, cell motility, and morphogenesis, and are also required for brain function. The compatibility between the tubulin-microtubule system and the antioxidative enzyme system in cells deteriorated by $\mathrm{PCOOH}$ is clearly demonstrated in this paper. The tubulin-microtubule system of differentiated PC12 cells decreased significantly with exposure to $\mathrm{PCOOH}$ dependent on concentration, while the three antioxidative enzymes increased in activity. This result indicates the limitations of the ability of an 
antioxidative enzyme to remove oxidative stress induced by hydrogen peroxide, lipid hydroperoxides, and superoxide. Our findings from the compatibility of the tubulin-microtubule system and antioxidative enzyme activity are very important for the understanding of brain function in individuals with dementia.

The microtubules should be sufficiently formed for proper function in the cells. Based on the facts of the decrease of microtubule formation and the increase of antioxidative enzyme activities in the cells deteriorated by $\mathrm{PCOOH}$, cells need additional antioxidative activities for normal viability. Therefore, the use of exogenous antioxidants should be considered.

\section{Acknowledgments}

This work was supported in part by a Grant-in-Aid for Young Scientists (B) from the Japan Society for the Promotion of Science (to Yukako Yamanaka) (No. 19700605) and a Grant-in-Aid for Scientific Research (C) from the Japan Society for the Promotion of Science (to Hiroshi Doi) (Nos. 20500731 and 23500985).

\section{Conflict of Interest}

The authors declare no conflict of interest.

\section{References}

1. Matsuyama, S.S.; Jarvik, L.F. Hypothesis: Microtubules, a key to Alzheimer disease. Proc. Natl. Acad. Sci. USA 1989, 86, 8152-8126.

2. Masliah, E.; Terry, R.D.; DeTeresa, R.M.; Hansen, L.A. Immunohistochemical quantification of the synapse-related protein synaptophysin in Alzheimer disease. Neurosci. Lett. 1989, 103, 234-239.

3. Iqbal, K.; Alonso, A.C.; Gong, C.X.; Khatoon, S.; Singh, T.J.; Grundke-Iqbal, I. Mechanism of neurofibrillary degeneration in Alzheimer's disease. Mol. Neurobiol. 1994, 9, 119-123.

4. Kawakami, M.; Ward, L.; Doi, H. Inhibition of tubulin guanosine-5'-triphosphate by lipid peroxide: protective effects og vitamin A derivatives. J. Am. Oil Chem. Soc. 1998, 75, 635-641.

5. Yomogida, K.; Yoshida-Yamamoto, S.; Doi, H. Roles Microtubules in Maintenance of Nerve Cell Netwaorks; InTech: Rijeka, Croatia, 2011; pp. 35-50.

6. Farooqui, A.A.; Horrocks, L.A. Plasmalogen-selective phospholipase A2 and its involvement in Alzheimer's disease. Biochem. Soc. Trans. 1998, 26, 243-246.

7. Hajimohammadreza, I.; Brammer, M.J.; Eagger, S.; Burns, A.; Levy, R. Platelet and erythrocyte membrane changes in Alzheimer's disease. Biochim. Biophys. Acta 1990, 1025, 208-214.

8. Nakagawa, K.; Fujimoto, K.; Miyazawa, T. $\beta$-carotene as a high-potency antioxidant to prevent the formation of phospholipid hydroperoxides in red blood cells of mice. Biochim. Biophys. Acta 1996, 1299, 110-116.

9. Pan, X.; Zhu, Y.; Lin, N.; Zhang, J.; Ye, Q.; Huang, H.; Chen, X. Microglial phagocytosis induced by fibrillar $\beta$-amyloid is attenuated by oligomeric $\beta$-amyloid: Implications for Alzheimer's disease. Mol. Neurodegener. 2011, 30, 45.

10. Emerit, J.; Edeas, M.; Bricaire, F. Neurodegenerative diseases and oxidative stress. Biomed. Pharmacother. 2004, 58, 39-46. 
11. Christen, Y. Oxidative stress and Alzheimer disease. Am. J. Clin. Nutr. 2000, 71, 621S-629S.

12. Al-Gubory, K.H.; Fowler, P.A.; Garrel, C. The roles of cellular reactive oxygen species, oxidative stress and antioxidants in pregnancy outcomes. Int. J. Biochem. Cell Biol. 2010, 42, 1634-1650.

13. Bhor, V.M.; Raghuram, N.; Sivakami, S. Oxidative damage and altered antioxidant enzyme activities in the small intestine of streptozotocin-induced diabetic rats. Int. J. Biochem. Cell Biol. 2004, 36, 89-97.

14. Kakkar, R.; Kalra, J.; Mantha, S.V.; Prasad, K. Lipid peroxidation and activity of antioxidant enzymes in diabetic rats. Mol. Cell. Biochem. 1995, 151, 113-119.

15. Kawakami, M.; Ward, L.; Doi, H. Mechanisms of tubulin modification by phosphatidylcholine hydroperoxides. Lipids 2000, 35, 205-211.

16. Mueller, H.W.; Purdon, A.D.; Smith, J.B.; Wykle, R.L. 1-O-alkyl-linked phosphoglycerides of human platelets: distribution of arachidonate and other acyl residues in the ether-linked and diacyl species. Lipids 1983, 18, 814-819.

17. Siqueira, I.R.; Fochesatto, C.; de Andrade, A.; Santos, M.; Hagen, M.; Bello-Klein, A.; Netto, C.A., Total antioxidant capacity is impaired in different structures from aged rat brain. Int. J. Dev. Neurosci. 2005, 23, 663-671.

18. Yamanaka, Y.; Yoshida, S.; Doi, H. NGF-induced neurite outgrowth of PC12 cells in the presence of phosphatidylcholine hydroperoxides: Implication for ageing. Mech. Ageing Dev. 2008, 129, 215-222.

19. O'Brien, E.T.; Voter, W.A.; Erickson, H.P. GTP hydrolysis during microtubule assembly. Biochemistry 1987, 26, 4148-4156.

20. Seckler, R.; Wu, G.M.; Timasheff, S.N. Interactions of tubulin with guanylyl-(beta-gamma-methylene)diphosphonate. Formation and assembly of a stoichiometric complex. J. Biol. Chem. 1990, 265, 7655-7661.

21. Doi, H.; Imanishi, T.; Iwami, K.; Ibuki, F. Is microtubule assembly not associated with GTP hydrolysis? Agric. Biol. Chem. 1991, 55, 245-246.

22. Benzi, G.; Marzatico, F.; Pastoris, O.; Villa, R.F. Influence of oxidative stress on the age-linked alterations of the cerebral glutathione system. J. Neurosci. Res. 1990, 26, 120-128.

23. Ochiai, T.; Soeda, S.; Ohno, S.; Tanaka, H.; Shoyama, Y.; Shimeno, H. Crocin prevents the death of PC-12 cells through sphingomyelinase-ceramide signaling by increasing glutathione synthesis. Neurochem. Int. 2004, 44, 321-330.

24. Ferrari, R.; Agnoletti, L.; Comini, L.; Gaia, G.; Bachetti, T.; Cargnoni, A.; Ceconi, C.; Curello, S.; Visioli, O. Oxidative stress during myocardial ischaemia and heart failure. Eur. Heart J. 1998, 19, B2-B11.

25. Halliwell, B. Oxidants and the central nervous system: Some fundamental questions. Is oxidant damage relevant to Parkinson's disease, Alzheimer's disease, traumatic injury or stroke? Acta Neurol. Scand. Suppl. 1989, 126, 23-33.

26. Imre, S.; Juhasz, E. The effect of oxidative stress on inbred mice of different ages. Mech. Ageing Dev. 1987, 38, 259-266.

27. Harman, D. Aging: A theory based on free radical and radiation chemistry. J. Gerontol. 1956, 11, 298-300. 
28. Barja, G. Rate of generation of oxidative stress-related damage and animal longevity. Free Radic. Biol. Med. 2002, 33, 1167-1172.

29. Muscari, C.; Giaccari, A.; Giordano, E.; Clo, C.; Guarnieri, C.; Caldarera, C.M. Role of reactive oxygen species in cardiovascular aging. Mol. Cell. Biochem. 1996, 160-161, 159-166.

30. Wickens, A.P. Ageing and the free radical theory. Respir. Physiol. 2001, 128, 379-391.

31. Pansarasa, O.; Bertorelli, L.; Vecchiet, J.; Felzani, G.; Marzatico, F. Age-dependent changes of antioxidant activities and markers of free radical damage in human skeletal muscle. Free Radic. Biol. Med. 1999, 27, 617-622.

32. Finkel, T. Oxidant signals and oxidative stress. Curr. Opin. Cell Biol. 2003, 15, 247-254.

33. Beckman, K.B.; Ames, B.N. The free radical theory of aging matures. Physiol. Rev. 1998, 78, 547-581.

34. Kedar, N.P. Can we prevent Parkinson's and Alzheimer's disease? J. Postgrad. Med. 2003, 49, 236-245.

35. Ansari, M.A.; Roberts, K.N.; Scheff, S.W. Oxidative stress and modification of synaptic proteins in hippocampus after traumatic brain injury. Free Radic. Biol. Med. 2008, 45, 443-452.

36. Halliwell, B. Oxidative stress and neurodegeneration: Where are we now? J. Neurochem. 2006, 97, 1634-1658.

37. Miyazawa, T.; Suzuki, T.; Fujimoto, K.; Kinoshita, M. Age-related change of phosphatidylcholine hydroperoxide and phosphatidylethanolamine hydroperoxide levels in normal human red blood cells. Mech. Ageing Dev. 1996, 86, 145-150.

38. Miquel, J.; Ramirez-Bosca, A.; Soler, A.; Diez, A.; Carrion-Gutierrez, M.A.; Diaz-Alperi, J.; Quintanilla-Ripoll, E.; Bernd, A.; Quintanilla-Almagro, E. Increase with age of serum lipid peroxides: Implications for the prevention of atherosclerosis. Mech. Ageing Dev. 1998, 100, 17-24.

39. Kinoshita, M.; Oikawa, S.; Hayasaka, K.; Sekikawa, A.; Nagashima, T.; Toyota, T.; Miyazawa, T. Age-related increases in plasma phosphatidylcholine hydroperoxide concentrations in control subjects and patients with hyperlipidemia. Clin. Chem. 2000, 46, 822-828.

40. Greene, L.A.; Tischler, A.S. Establishment of a noradrenergic clonal line of rat adrenal pheochromocytoma cells which respond to nerve growth factor. Proc. Natl. Acad. Sci. USA 1976, $73,2424-2428$.

41. Kolla, N.; Wei, Z.; Richardson, J.S.; Li, X.M. Amitriptyline and fluoxetine protect PC12 cells from cell death induced by hydrogen peroxide. J. Psychiatry Neurosci. 2005, 30, 196-201.

42. Morikawa, K.; Shimokawa, H.; Matoba, T.; Kubota, H.; Akaike, T.; Talukder, M.A.; Hatanaka, M.; Fujiki, T.; Maeda, H.; Takahashi, S.; et al. Pivotal role of Cu,Zn-superoxide dismutase in endothelium-dependent hyperpolarization. J. Clin. Invest. 2003, 112, 1871-1879.

43. Wheeler, C.R.; Salzman, J.A.; Elsayed, N.M.; Omaye, S.T.; Korte, D.W., Jr. Automated assays for superoxide dismutase, catalase, glutathione peroxidase, and glutathione reductase activity. Anal. Biochem. 1990, 184, 193-199.

(C) 2012 by the authors; licensee MDPI, Basel, Switzerland. This article is an open access article distributed under the terms and conditions of the Creative Commons Attribution license (http://creativecommons.org/licenses/by/3.0/). 